\title{
We Can Do It: Uma Análise do Perfil Feminino de Computação no Mercado de Trabalho
}

\author{
Maynara de Oliveira Walter \\ Universidade Tecnológica Federal do \\ Paraná \\ Dois Vizinhos, PR, Brasil \\ maynarawalter@outlook.com
}

\author{
Natália Tiemi Yada \\ Universidade Tecnológica Federal do \\ Paraná \\ Dois Vizinhos, PR, Brasil \\ natalia.yada@gmail.com
}

\author{
Jéssica Iara Pegorini \\ Universidade Tecnológica Federal do \\ Paraná \\ Dois Vizinhos, PR, Brasil \\ pegorini@alunos.utfpr.edu.br
}

\author{
Arielyn Pádua Silva \\ Universidade Tecnológica Federal do \\ Paraná \\ Dois Vizinhos, PR, Brasil \\ arielyn@alunos.utfpr.edu.br
}

\author{
Alinne Cristinne Correa Souza \\ Universidade Tecnológica Federal do \\ Paraná \\ Dois Vizinhos, PR, Brasil \\ alinnesouza@utfpr.edu.br
}

\begin{abstract}
Women have always struggled to hold their own in the employment market. In computing area is not different as men are still the majority of professionals.Thus, this paper presents the results of a survey conducted throug female public in different computing organizations. The survey aims to identify their satisfaction, fellings, challenges and perceptions about the role played in this area. The initial results are promising and indicate low participation of women in comparison as men, highlighting the importance of to create political to promote the women participation in the industry and courses of Computer.
\end{abstract}

\section{KEYWORDS}

Women in computing, Gender inequality, Employment market

\section{INTRODUÇÃO}

A participação feminina no mercado de trabalho apresentou crescimento significativo na última década quando comparada aos anos anteriores. Todavia há um longo caminho para ser percorrido, uma vez que a Organização Internacional do Trabalho aponta que a taxa mundial de participação das mulheres na força de trabalho no ano de 2018 apresentou-se em 48,5\%, com 26,5\% abaixo do resultado de participação masculina [1].

No Brasil as mudanças culturais, o investimento em educação e a conquista de direitos motivaram a estimativa apresentada em 2019 pelo Instituto de Pesquisa Econômica Aplicada (INEP) de que até 2030, a participação feminina no mercado de trabalho nacional será maior do que a dos homens. A pesquisa, que não considera os efeitos de uma possível reforma previdenciária, revela que 64,3\% das mulheres em idade ativa (17 a 70 anos) estarão empregadas ou buscando emprego [2]. Esse número nos anos 90 era de 56,1\%, taxa que não aumentou sozinha: as mulheres brasileiras também chegaram ao mercado mais escolarizadas do que os homens, se mostrando maioria no ensino superior [3]. Portanto, as mulheres estão buscando e conquistando competitividade num mercado que passou cada vez mais a exigir qualificação profissional.

Apesar das projeções mostrarem crescimento feminino no mundo laboral até 2030, numa certa "vantagem" sobre a realidade participativa dos homens, elas também mostram que 35,5\% das mulheres em idade ativa estarão fora do mercado, majoritariamente em decorrência de obstáculos domésticos [4].

Nesse contexto, a balança da desigualdade de gênero volta a pesar negativamente para as mulheres: são minoria em cargos de liderança, que pagam mais e maioria na informalidade, onde ganham menos.

Uma pesquisa da Universidade Princeton aponta que homens propendem a candidatarem-se para uma vaga quando acreditam possuir $60 \%$ das competências necessárias ao cargo, enquanto as mulheres só o fazem quando julgam possuir $100 \%$ dos requisitos para um bom desempenho [5]. Apesar das mulheres serem a maioria dentro das faculdades brasileiras, as mesmas encontram-se vulneráveis ao aumento da desigualdade de gênero no mercado de trabalho por conta da automatização de cargos ocupados em sua maioria pelo perfil feminino, como secretariado e atendimento ao cliente [6].

É importante destacar que com a ascensão das categorizadas como profissões do futuro, que estão relacionadas aos cursos de Ciência, Engenharia, Matemática e Tecnologia este quadro se agrava, uma vez que o Brasil numa lista de 12 nações, é o $6^{\circ}$ país da América Latina no ranking de formação de profissionais mulheres para a "indústria 4.0 ", já que historicamente trata-se de um setor considerado masculino [7].

O número de cursos de computação cresceu $58,6 \%$ nos últimos 24 anos no Brasil, já o percentual de mulheres matriculadas nesses mesmos cursos caiu de 34,8\% para 15,5\% [8]. A ironia é constatada justamente ao fato de que a primeira turma de Ciência da Computação do Instituto de Matemática e Estatística (IME) de São Paulo, em 1974, possuía 20 alunos, sendo 14 mulheres e 6 homens. Por outro lado, a turma de 2016 do IME contava com 41 homens e apenas 6 mulheres [9]. Esses números não refletem apenas a situação brasileira, segundo o Centro Nacional de Estatísticas da Educação dos Estados Unidos [10], as mulheres representavam aproximadamente 37\% dos americanos cursando Ciência da Computação entre 1984 e 1985, porém em 2010 este percentual reduziu para $20 \%$.

Apesar das mulheres ainda serem a minoria em algumas áreas no mercado de trabalho, é notável as conquistas feministas em que as mesmas estão cada vez mais ocupando espaços tradicionalmente dominados por homens. No entanto, essa realidade ainda não pode ser generalizada ou observada na área de computação e afins. 
Diante disso, visando identificar e analisar o panorama sobre a participação do perfil feminino em empresas na área de computação na cidade de Dois Vizinhos no Paraná, um survey foi planejado e executado com mulheres atuantes no mercado de trabalho na área de computação. Essa pesquisa torna-se relevante em função da cidade tratar-se de um polo tecnológico regional, carecer de conteúdo informativo acerca da participação feminina nesta área e estimular as mulheres à disputarem cargos de liderança nas empresas.

Assim, este artigo tem o intuito de apresentar o processo de planejamento do survey, a condução e os resultados obtidos. Além disso, para apoiar o domínio e a disseminação da realidade das mulheres que atuam nessas organizações e suas percepções diante do cenário de desigualdade de gênero na área, serão apresentadas algumas perspectivas de iniciativas que podem ser realizadas e esforços que merecem atenção.

Este artigo está organizado da seguinte forma: na Seção 2 são apresentadas as contribuições femininas para a história da Computação. Na Seção 3 são abordados trabalhos relacionados que contribuíram para o cenário científico de pesquisa da presença das mulheres na ciência e computação. Na Seção 4 é apresentada a forma como foi conduzido o survey. Na Seção 5 são apresentados e discutidos os resultados alcançados. Por fim, na Seção 6 as considerações finais e trabalhos futuros são apresentados.

\section{HISTÓRIA DAS MULHERES NA COMPUTAÇÃO}

Desde os princípios da ciência tornou-se popular a ideia de que a gnose científica era uma atribuição exclusiva ao domínio masculino. Cruz [11] ressalta que até o início do séc. XX, o campo de estudo científico era visto como inapropriado para mulheres. Essa visão era mantida, uma vez que o cérebro feminino era considerado inferior ao masculino e presumivelmente desprovido da inteligência necessária para a realização de tarefas tão complexas.

Segundo Bandeira [12], as mulheres que porventura conseguiam ultrapassar esses obstáculos eram invisibilizadas, independentemente do grau de importância de sua contribuição para o conhecimento científico, ainda que a teoria/invenção/ideia/princípio fosse considerada relevante somente recebia a devida autenticação quando apresentada e aprovada por um homem.

Atualmente, com a crescente conquista de espaço por parte das mulheres, é possível observar o reconhecimento de trabalhos desenvolvidos por estas nos variados âmbitos da ciência. Um desses campos científicos é a Computação, as primeiras referências de presença feminina nessa área ocorreu no séc. XIX com a matemática e Condessa de Lovelace: Ada Augusta Byron King.

Ada Lovelace, de origem inglesa, ficou conhecida como a primeira mulher a programar na história, após criar sequências de instruções notando as funções lógicas e aritméticas na Máquina de Babbage. Técnicas de programação como comando condicional, tipos de dados, operadores, matrizes e loops, além do uso do sistema binário ao invés do decimal são exemplos de seus inventos [13].

Outra representante importante é a americana $\mathrm{PhD}$ em matemática Grace Murray Hopper, que é destaque histórico nas linguagens de programação: desenvolveu programas para um dos precursores do computador moderno, o Mark I; trabalhou no primeiro compilador da história conhecido como $A-2$ e na linguagem matemática $M A T H-$ MATIC; em 1955 participou da equipe que elaborou especificações para a linguagem FLOW-MATIC, que contribuiu imensamente para a formulação da Linguagem Comum Orientada para os Negócios (do inglês, COmmon Business Oriented Language - COBOL). Hopper ainda idealizou o conceito de sub-rotinas para aproveitamento de blocos de comando e criou os termos bug e debug após encontrar uma mariposa nos circuitos do Mark I [13].

A Assembly, primeira linguagem de montagem da história, foi criada na déc. de 50 pela inglesa Kathleen Booth que escreveu a linguagem para o computador ARC (Automatic Relay Calculator) [14]. Assim como Booth, outras figuras femininas abrilhantam a história da Computação como: as estrelas da NASA, Katherine Johnson, Dorothy Vaughn e Mary Jackson, que além de enfrentarem as barreiras do sexismo tinham de lidar com a segregação racial norte-americana enquanto mulheres negras. Margaret Hamilton e seu software que salvou a missão Apollo 11. Hedy Lamarr e seu sistema de comunicações para as forças armadas que serviu de base para a invenção do WiFi [15].

Mais recentemente, nomes como Carol Shaw, Shafrifa Goldwasser e Anita Borg são exemplos de mulheres de destaque contributivo ao histórico computacional [16]. Em abril de 2019 a cientista Katie Bouman foi destaque após o sucesso do algoritmo criado que foi capaz de entender milhares de dados astronômicos. Esse resultado foi responsável pela primeira imagem de um buraco negro na história [17].

Portanto, é notável que as mulheres tiveram seu marco na história de computação. No entanto, essa participação ativa foi na evolução do software por ser um trabalho que não envolve atendimento ao público, o que garantia a invisibilidade e consequentemente mantinha distância dos olhares.

\section{TRABALHOS RELACIONADOS}

Alguns trabalhos tem discutido sobre a participação das mulheres na área da computação tanto no âmbito da indústria quanto na academia.

Olinto [18], discute a desigualdade de gênero no âmbito científico, analisando os meios que levam à segregação horizontal: onde as mulheres são guiadas à caminhos completamente diferentes dos oferecidos aos homens, especialmente nas responsabilidades domésticas e familiares assim realizando escolhas de carreira marcadas pelo fator gênero. É importante destacar que nos últimos anos tem sido investigado o perfil das mulheres graduandas em cursos da área computacional e as estatísticas de participação destas quando comparadas à participação masculina nas instituições de ensino superior no Brasil. Nesse contexto, a baixa participação feminina e a necessidade de políticas de fomento para a reversão deste quadro tem sido abordadas com maior frequência em diferentes estudos [19], [20], [21], [22] e [23].

Oliveira, Mirella e Prates [22] buscam apresentar uma breve base para o traçado de um perfil para as mulheres na Computação, objetivando contribuir na elaboração de projetos que atraiam meninas para a área e retenham as que já estão na mesma. A partir da pesquisa realizada por meio de questionário aplicado à estudantes e profissionais constatou-se pouco preconceito com a área, mais professoras do que alunas relataram sofrer preconceito por serem 
mulheres e as profissionais com mais de 40 anos relataram sofrer menos discriminação do que as mais jovens. As autoras destacam a intenção em se aprofundar qualitativamente nas perguntas para levantamentos futuro.

Portanto, diante dos estudos apresentados, o presente artigo diferencia-se uma vez que visa realizar uma análise do perfil feminino especificamente no mercado de trabalho na área de computação na cidade de Dois Vizinhos no sudoeste do Paraná.

\section{AVALIAÇÃO EXPERIMENTAL}

Nesta seção será detalhado o survey conduzido para identificar e analisar o panorama sobre a participação do perfil feminino em empresas na área de computação na cidade de Dois Vizinhos no Paraná. O survey foi planejado seguindo o processo proposto por Kasunic [24] para design efetivo de surveys para a área de engenharia de software. Além disso, foram utilizados direcionamentos descritos por Kitchenham e Pfleeger [25]. Nesse sentido, o processo de condução do survey envolveu sete etapas, representadas na Figura 1.

\subsection{Identificação dos objetivos de investigação}

Em virtude do objetivo principal da condução do survey ser a identificação da atuação do perfil feminino em empresas na área de computação, bem como realidade das mulheres que atuam nessas organizações e suas percepções diante do cenário de desigualdade de gênero nessa área, procurou-se estabelecer as informações necessárias que deveriam ser coletadas. Assim, inicialmente procurouse reconhecer as possíveis empresas, identificar as áreas de atuação, descobrir a situação atual no mercado de trabalho, caracterizar a possibilidade de crescimento, identificar o nível de valorização no ambiente de trabalho, detectar se as principais dificuldades enfrentadas estão relacionadas à preconceitos ou descriminação por ser mulher, constatar se em algum momento foi prejudicada no seu ambiente de trabalho por ser mulher.

\subsection{Identificação e caracterização do público-alvo}

O público-alvo definido para participar do survey é composto por mulheres que estejam cursando ou sejam formadas em cursos superiores de computação (ciência da computação, sistemas de informação, engenharia de computação ou engenharia de software); e estejam estagiando ou trabalhando em empresas na área de computação na cidade de Dois Vizinhos. Após a definição do públicoalvo, foi planejado o processo de obtenção de amostras.

\subsection{Planejamento de amostragem}

O processo de obtenção de amostras da população, foi planejado para seguir uma metodologia que oferecesse subsídios para obtenção de resultados da amostra que fossem representativos de toda a população. Nesse contexto, como estratégia para identificar diferentes perfis femininos foi considerado localizar as mulheres em atuação nas empresas. A identificação das mulheres foi realizada por meio do contato com as empresas e com o auxílio de alunas que atuam nessas empresas.

\subsection{Planejamento e escrita do questionário}

Nesta etapa do processo, os objetivos pré-definidos na primeira etapa foram retificados, bem como a forma como os dados das participantes seriam coletados. Considerando que não ocorreu contato presencial com as participantes, foi definido que o survey seria disponibilizado em formato de questionário eletrônico.

O questionário foi desenvolvido utilizando a ferramenta Google Forms ${ }^{1}$. As questões foram estruturadas em três seções e estão disponíveis em: https://forms.gle/T3aYQtSPfbMVAGga8.

A primeira seção seção contém uma apresentação do survey em que é descrito o objetivo do mesmo e o público-alvo. A segunda seção foi desenvolvida para coletar informações que caracterizam os participantes, são elas: idade do participante, afiliação, vínculo com a empresa, tempo do vínculo, curso superior e instituição de ensino. Por fim, a última seção teve a finalidade de coletar informações a respeito do comportamento e percepções das mulheres relacionadas a valorização, preconceito, discriminação, bem como incentivos à participação das mulheres na área de computação. Foi disponibilizado um espaço para as mulheres descreverem sobre possíveis preconceitos ou discriminações que tenham sofrido. Após o desenvolvimento do questionário eletrônico, foi realizada uma execução piloto, visando analisar a validade do instrumento.

\subsection{Execução do survey piloto}

Segundo Kasunic [24] conduzir um survey piloto é fundamental, pois permite detectar possíveis problemas existentes no mesmo, verificar se as perguntas são compreensíveis, se as perguntas certas foram feitas para atingir o objetivo, e quanto tempo os participantes levam para completarem o questionário.

Uma forma de verificar a validade de um instrumento é por meio da avaliação do seu conteúdo. Para avaliar o survey foi utilizado quatro questões abertas propostas por Hauck et. al [26], que são: (1) o questionário contém tudo que é esperado para contemplar o seu objetivo? (2) o questionário contém quaisquer informações não desejáveis ou desnecessárias ao contexto e objetivo da pesquisa? (3) você conseguiu compreender adequadamente as perguntas? (4) existe algum erro ou inconsistência no questionário?. Além destas questões também foram consultadas as opiniões de especialistas [27].

Nesse contexto, um grupo de quatro participantes distribuídas entre formadas e não formadas, estagiando e trabalhando foram convidadas por email para participar do teste piloto. Essas participantes, foram selecionadas pelos critérios de disponibilidade e proximidade, participaram do estudo piloto respondendo as questões propostas por Hauck et. al [26] e enviaram feedbacks sobre o survey. A avaliação das participantes foi positiva, com sugestões para: reduzir o número de perguntas, deixar algumas não obrigatórias; e incluir uma pergunta aberta.

\subsection{Distribuição do questionário}

A partir dos feedbacks e consultas com especialistas, alguns ajustes foram realizados para que o mesmo pudesse ser distribuído para as participantes. O questionário foi distribuído por e-mails e disponibilizado nas plataformas das empresas. Essa distribuição ocorreu entre 01 e 30 de agostos de 2019 para 40 mulheres. Após este período,

\footnotetext{
${ }^{1}$ Mais informações podem ser obtidas em: https://www.google.com/forms/about/
} 


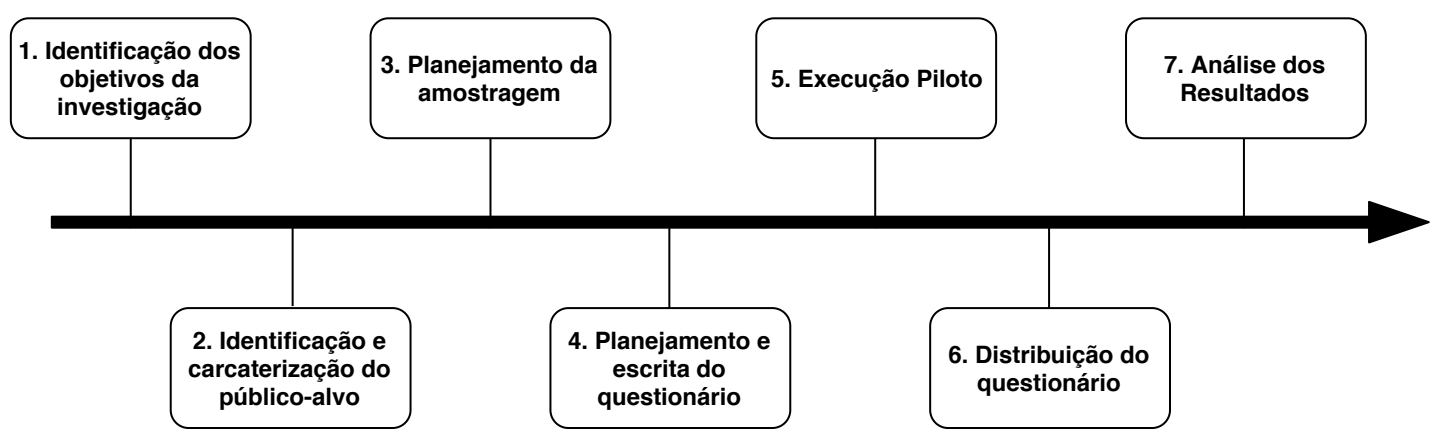

Figure 1: Processo adotado na condução do survey

os dados coletados foram analisados, visando compreender a atuação do perfil feminino na área de computação em organizações, bem como suas percepções.

\section{DISCUSSÃO E ANÁLISE DOS RESULTADOS}

O survey foi respondido por 31 mulheres, atuantes em diferentes áreas da computação, de diferentes empresas. Os resultados serão apresentados de acordo com as seções criadas no questionário, conforme apresentado na Seção 4.4.

\subsection{Perfil Básico}

As perguntas relacionadas ao perfil básico visam apresentar informações mais gerais das participantes incluindo idade, formação e atuação profissional.

Dentre os dados analisados, é possível observar que a maior parte das participantes que responderam a pesquisa já são formadas em algum curso superior na área de tecnologia, e trabalham em empresas de software há algum tempo, exercendo funções que vão desde desenvolvedoras até Product Owner (PO). Algumas relataram dificuldades ao ingressar no mercado de trabalho, mas a maioria delas afirmou que não teve dificuldades para entrar na empresa em que trabalham e que a mesma também oferece oportunidades de crescimento profissional.

A Figura 2 representa a idade das participantes do survey, onde é possível observar que a grande maioria encontra-se na faixa etária entre 26 a 30 anos, percentual esse que representa $35,5 \%(11 / 31)$ do total. As participantes com até 21 anos, representam 25,8\% (8/31), enquanto que 16,1\% (5/31) têm idade entre 22 e 25 anos. Os outros $22,6 \%(7 / 22)$ representam as participantes com idade superior a 30 anos.

A Figura 3 ilustra que $83,9 \%$ das participantes já trabalham na área de tecnologia, o que representa 26 mulheres. Os outros $16,1 \%$ correspondem às 5 mulheres restantes que fazem estágio na área.

Quando questionadas em relação ao tempo em que já trabalham na área, a média de tempo de trabalho foi de 71 meses. Sendo que o menor tempo de trabalho é de 1 mês e o maior é de 228 meses, conforme pode ser visto a Figura 4 .

Quanto a área de formação das participantes, 64,5\% (20/31) delas disseram que já são formadas em algum curso superior, enquanto que 35,5\% (11/31) ainda estão cursando a graduação (Figura 5) .

Conforme mostra a Figura 6, os cursos que mais apareceram no currículo das participantes são os cursos Sistema de Informação e

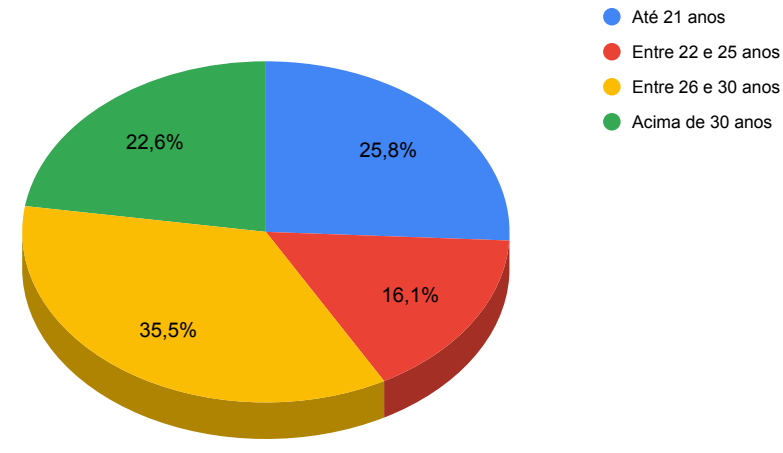

Figure 2: Faixa etária das participantes do survey.

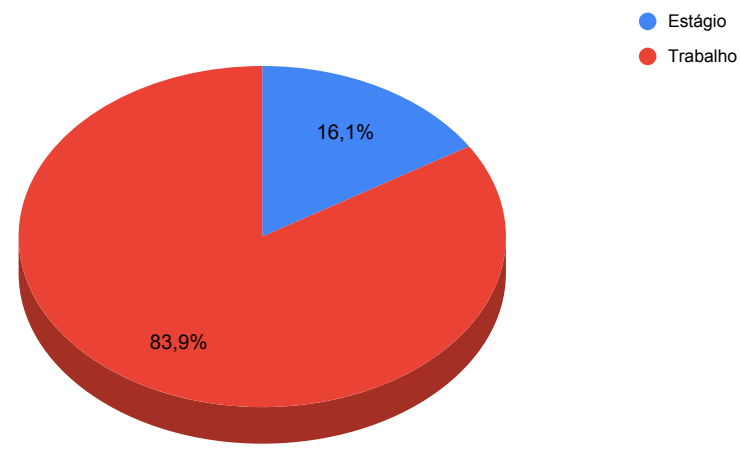

Figure 3: Percentual de participantes que trabalham ou fazem estágio na área.

Engenharia de Software. Vale ressaltar que 2 das participantes que atualmente trabalham na área de tecnologia, não cursaram nada diretamente ligados com a área de computação, sendo que uma delas cursou Administração e a outra Ciências contábeis e Direito, e que algumas das participantes cursaram duas faculdades diferentes. 


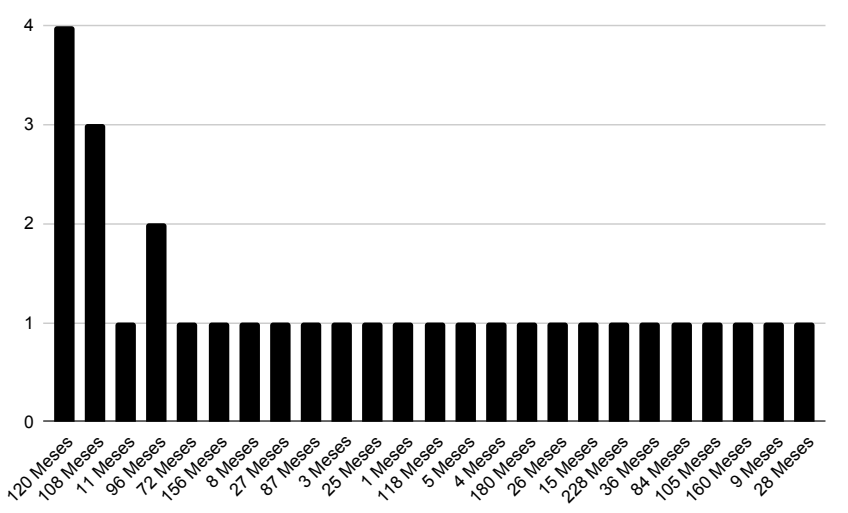

Figure 4: Tempo em meses de trabalho na área de tecnologia.

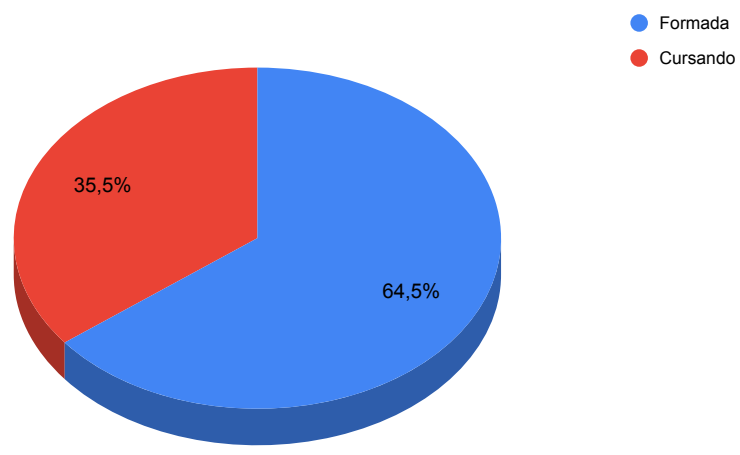

Figure 5: Relação das participantes formadas $X$ cursando a graduação.

Ao serem questionadas sobre as instituições de ensino em que cursam ou cursaram a graduação, as instituições com maiores números de egressas e ingressas são a UNISEP, UTFPR e VIZIVALI com $45,5 \%, 33,3 \%$ e 9,1\% respectivamente (Figura 7).

\subsection{Perfil Comportamental}

As perguntas relacionadas ao perfil comportamental visam identificar as percepções das participantes referentes à sua valorização no mercado de trabalho, possibilidade de crescimento, se as principais dificuldades enfrentadas estão relacionadas ao preconceito, descriminação e se em algum momento foi prejudicada no seu ambiente de trabalho por ser mulher.

Quando questionadas se indicariam algum curso superior na área de TI para outras mulheres, 12 delas disseram que sempre indicariam, o que representa $38,7 \%$ das 31 participantes. No restante, $35,5 \%$ (11/31) respondeu que na maioria das vezes indicaria, e $9,7 \%$ (3/31) disse que raramente indicaria um curso na área de TI para outras mulheres (Figura 8).

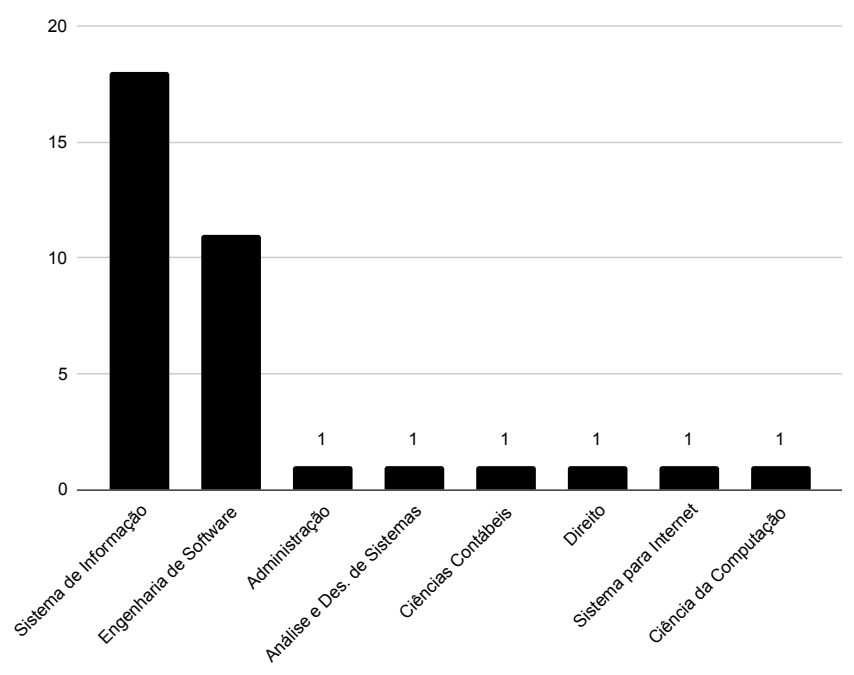

Figure 6: Relação dos cursos de graduação cursados pelas participantes.

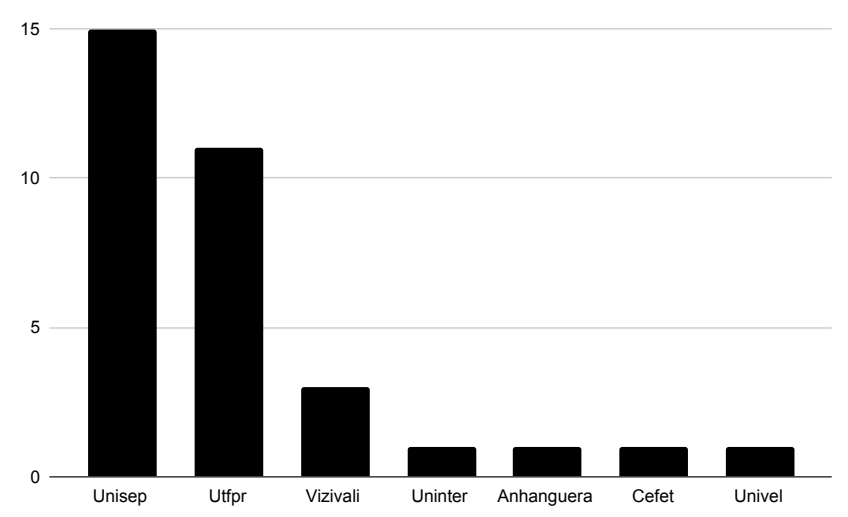

Figure 7: Relação das instituições de ensino das participantes.

Levando em consideração que um profissional de tecnologia pode atuar em diversas áreas, 10 participante trabalham como Analistas de teste, 8 com desenvolvimento, 5 como PO, 3 como Product Designer, 3 como Analistas de Negócios, e por fim 1 como Analista de Processos e 1 como Analista de Atendimento, conforme pode ser visto na Figura 9.

Tendo em vista que algumas vezes as pessoas encontram dificuldades para ingressar no mercado de trabalho após o término da graduação, as participantes foram questionadas sobre as suas dificuldades vivenciadas. Nesse sentido 22 delas, representando $71 \%$ do total, afirmaram que não tiveram dificuldades para encontrar um trabalho na área, enquanto que 29\% (9/31) das participantes relataram que tiveram um pouco de dificuldade (Figura 10).

Seguindo por essa linha, 87,1\% (27/31) das participantes disseram que a empresa que trabalham oferece oportunidades de crescimento 


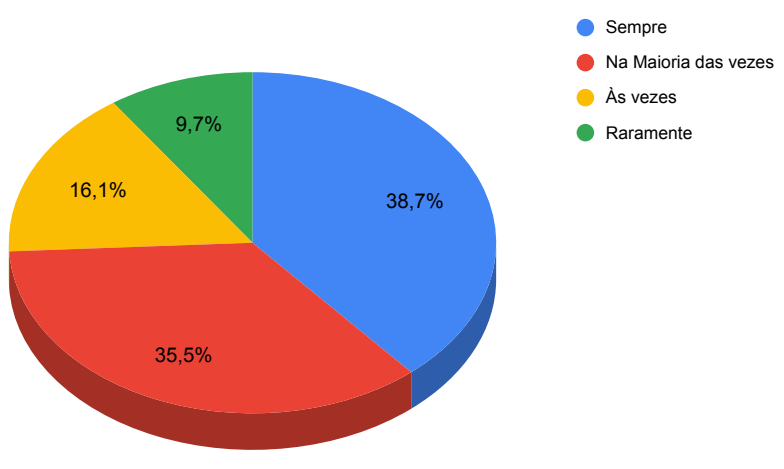

Figure 8: Relação das participantes que indicariam cursos na área de tecnologia para outras mulheres

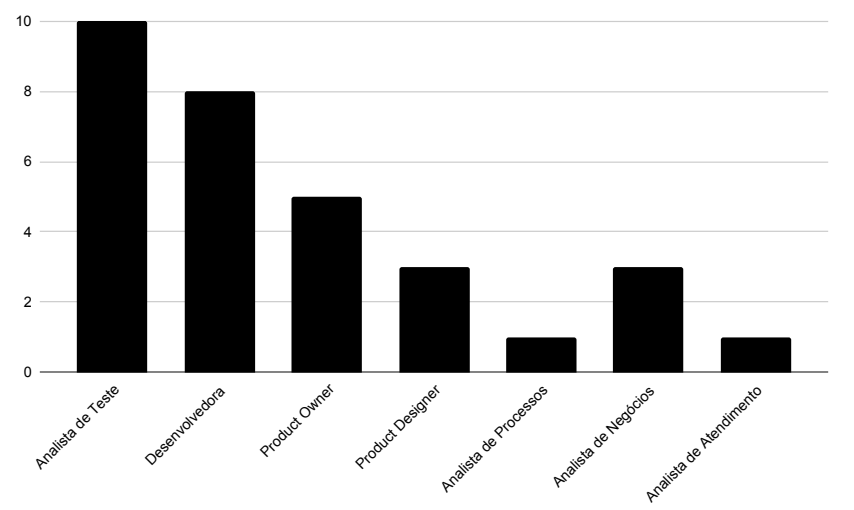

Figure 9: Relação de cargos que as participantes ocupam nas empresas.

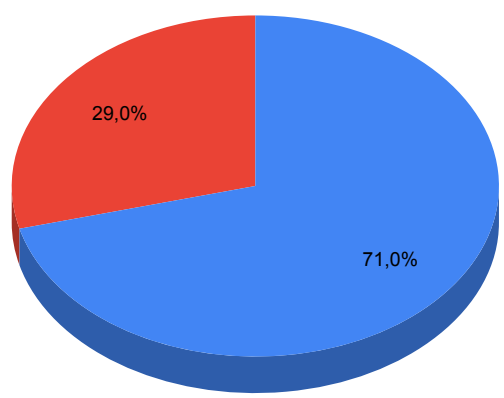

Sim

- Não

Figure 10: Percentual de dificuldade de ingresso no mercado de trabalho. profissional, enquanto que $12,9 \%$ (4/31) afirmaram que essa possibilidade não existe dentro da empresa em que trabalham (Figura 11).

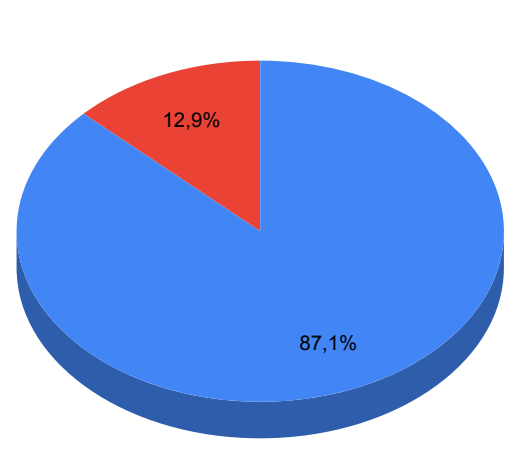

Sim

- Não

Figure 11: Percentual da possibilidade de crescimento profissional dentro da empresa.

Levando em conta que dentre as participantes do survey algumas trabalham em empresas muito grandes e outras trabalham em empresas de pequeno porte, elas foram questionadas sobre o número de mulheres que trabalham diretamente com elas, onde 22 delas afirmaram que trabalham diretamente com 1 a 4 mulheres, e apenas uma delas, disse que em seu setor trabalham de 11 a 15 mulheres conforme Figura 12.

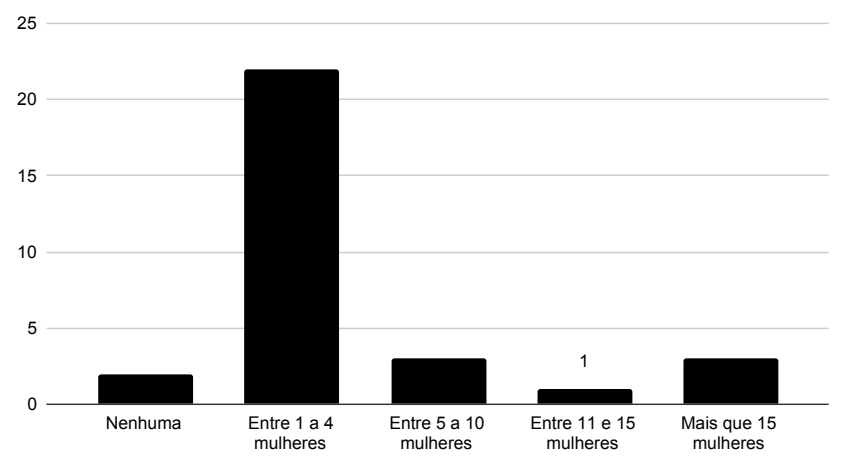

11 -

Figure 12: Percentual do número de mulheres que trabalham juntamente com a participante.

Quando questionadas sobre o cargo ocupado dentro da empresa, apenas 4 delas disseram que ocupam um cargo alto, enquanto que a maioria delas disseram que apenas conhecem alguém que ocupa um alto cargo dentro da empresa (Figura 13).

As participantes também foram questionadas sobre como são tratadas dentro da empresa em que trabalham, e a Figura 14 mostra que $45,2 \%$ (14/31) das participantes sentem-se valorizada na maioria das vezes em seu ambiente de trabalho. Enquanto que 19,4\% (6/31) 


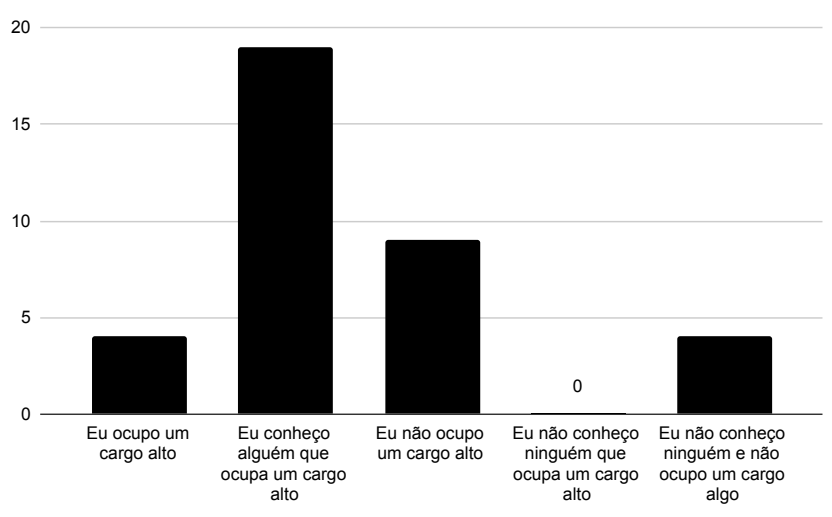

Figure 13: Relação dos cargos ocupados pelas participantes.

sempre se sente valorizada. Destaca-se a resposta de uma das participantes, que afirma que raramente se sente valorizada dentro do ambiente de trabalho.

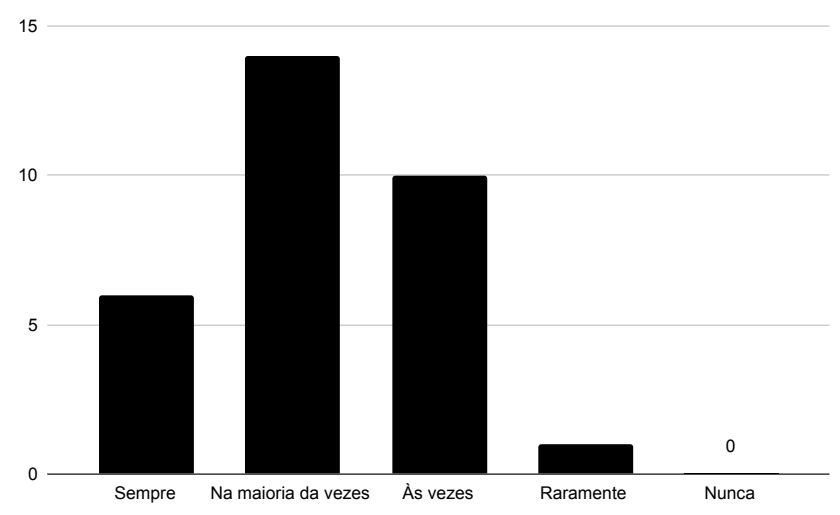

Figure 14: Números de participantes que se sentem valorizadas no ambiente de trabalho

Seguindo ainda nesta linha, 54,8\% (17/31) das participantes que as vezes se sentem ou já se sentiram prejudicadas no seu ambiente de trabalho pelo fato de ser mulher. Por outro lado, 22,6\% (7/31) disseram que nunca se sentiram prejudicadas por esse fato. Novamente uma das participantes afirmou que na maioria das vezes se sente prejudicada por ser mulher (Figura 15).

$45,2 \%$ (14/31) das participantes disseram que nunca sofreram nenhum tipo de discriminação ou preconceito no ambiente de trabalho. É importante destacar que 29\% (9/31) do total já sofreu alguma discriminação em algum momento e 3,2\% (1/31) delas disseram que na maioria das vezes sofre discriminação ou preconceito por ser mulher conforme pode ser visto na Figura 16.

Por fim, as participantes puderam falar abertamente sobre quais os tipos de preconceito que sofrem ou já sofreram dentro das empresas, bem como qual a sua opinião acerca de programas que visam incentivar a inserção de mulheres na área de computação. Algumas delas falaram que "as vezes por ser mulher as pessoas tendem a

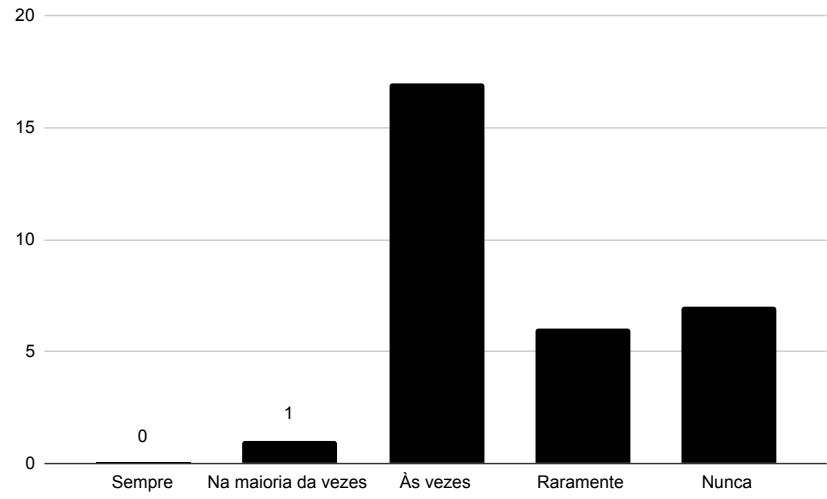

Figure 15: Número de participantes que se sentem prejudicadas por serem mulheres no ambiente de trabalho.

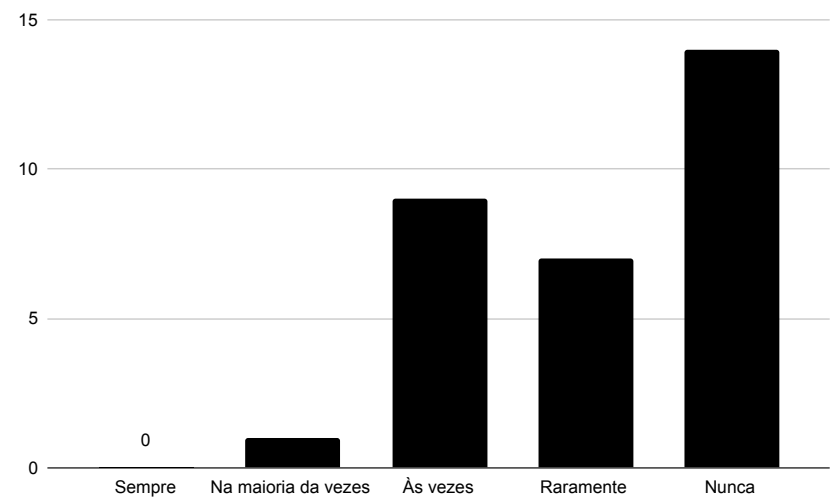

Figure 16: Número de participantes que acham que sofreram algum tipo de preconceito ou discriminação no ambiente de trabalho.

achar que você não entende nada na área técnica" e sobre os programas "acha maravilhosa essa ideia, pois é preciso mais mulheres na área". Outra participante comentou que "como seu papel é cobrar as coisas da equipe que é formada por $99 \%$ homens, muitas vezes acaba tendo que ficar repetindo inúmeras vezes a mesma situação" e sobre o programa "acha ótima a ideia".

Uma das participantes disse que "sofreu preconceito quando seus líderes dentro da empresa não deram credibilidade ao seu trabalho e sobre as respostas sobre questionamentos técnicos, sendo que depois de responder, perguntaram aos homens da equipe se o que havia respondido estava correto" e fala ainda que "acha a ideia do programa interessante, pois as mulheres têm a capacidade de desempenhar com qualidade e excelência qualquer papel relacionado a computação". Outra participante disse, que com ela "o tratamento dentro da empresa é mais didático, e que tem que mostrar o dobro de trabalho e resultado para que a sua habilidade tenha o mesmo valor que a dos meninos" e "acha que esses programas são extremamente necessários”. 


\section{CONSIDERAÇÕES FINAIS}

Este artigo apresentou planejamento, execução e os resultados da execução de um survey visando identificar a realidade das mulheres que atuam na área de computação e suas percepções. Para isso, foi realizada uma análise dos perfis de mulheres que já atuam nessa área em empresas na cidade de Dois Vizinhos no Paraná, buscando compreender suas percepções em relação a esse cenário de desigualdade.

Foi possível observar que a maioria das participantes são formadas na área de computação e veem um potencial crescimento de carreira na empresa em que trabalha atualmente, além de informar que, não tiveram dificuldades em entrar no mercado de trabalho. Isso demonstra uma assertividade, pois além da área de computação gerar diversas oportunidades de emprego, também pode ser um indicativo de que as mulheres são mais decididas a terminarem o curso e em seguida atuar na área de trabalho.

Apesar dos aspectos positivos, ainda é notável que a maioria dessas mulheres não trabalham em cargos compatíveis com as suas afinidades ou preferências, afirmando ainda mais as estatísticas apresentadas na Seção 1. Além disso, é importante destacar a baixa porcentagem das mulheres atuando na área de computação, o que reduz suas chances assumirem cargos altos nas organizações. Essas chances podem ser reduzidas em função de preconceitos e/ou discriminações, logo impactando no papel que a mulher pode desempenhar em ser uma autoridade em suas equipes, demonstrar conhecimento e ser valorizada na organização.

Portanto, com os resultados alcançados foi possível concluir que o desafio para alcançar uma igualdade de gênero na área de computação é contínuo e, que ainda existe preconceito em relação ao público feminino dominar conhecimentos nessa área. Além disso, foi notável o apoio dessas mulheres a outras que possuem interesse em ingressar em cursos de computação e o quão importante são os grupos de incentivo para conseguir mudar essa realidade atual.

Uma nova perspectiva de pesquisa futura são: (i) realizar essa pesquisa no sudoeste do Paraná, contemplando outras cidades; (ii) analisar a relação, as similaridades e as diferenças da atuação do público feminino na academia e na indústria na área de computação; e (iii) realizar uma pesquisa com o público masculino a fim de identificar seu ponto de vista com relação às mulheres que ocupam cargos de gestão.

\section{REFERENCES}

[1] National Center for Education Statistics (NCES). Perspectivas sociais e de emprego no mundo: Tendências para mulheres, 2018. URL https://www.ilo.org/ brasilia/noticias/WCMS_619819/lang--pt/index.htm.

[2] Instituto de Pesquisa Econômica Aplicada (IPEA). Decomposição e projeção da taxa de participação do brasil utilizando o modelo idade-períodocoorte, 1992 a 2030, 2019. URL http://www.ipea.gov.br/portal/index.php? option=com_content\&view=article\&id=34752:pesquisa- mostra-tendencia-decrescimento-na-participacao-do-brasileiro-no-mercado-de-trabalho\&catid $=10$ : disoc\&directory $=1$.

[3] Instituto Nacional de Estudos e Pesquisas Educacionais Anísio Teixeira (INEP) Censo da educação superior 2017, 2017. URL http://portal.mec.gov.br/index.php? option $=$ com_docman $\&$ view $=$ download $\&$ alias $=97041-$ apresentac $-\mathrm{a}-\mathrm{o}-\mathrm{censo}-$ superior-u-ltimo\&category_slug=setembro-2018-pdf\&Itemid=3019.

[4] Instituto Brasileiro de Geografia e Estatística (IBGE). Outras formas de trabalho: 2018, 2018. URL https://biblioteca.ibge.gov.br/index.php/biblioteca-catalogo? view $=$ detalhes\&id $=2101650$.

[5] Karen Garcia. Mulheres e liderança: dicas de executivas brasileiras para superar obstáculos no mercado de trabalho, 2019. URL https //oglobo.globo.com/celina/mulheres-lideranca-dicas-de-executivas-brasileiraspara-superar-obstaculos-no-mercado-de-trabalho-23690481.
[6] Daine Costa. Baixa participação nas profissões do futuro ameaça emprego feminino, 2019. URL https://oglobo.globo.com/economia/baixa-participacao-nasprofissoes-do-futuro-ameaca-emprego-feminino-23425177?versao=amp.

[7] O Globo. "baixa participação nas profissões do futuro ameaça emprego feminino", 2019. URL https://oglobo.globo.com/economia/baixa-participacao-nasprofissoes-do-futuro-ameaca-emprego-feminino- 23425177.

[8] Instituto Nacional de Estudos e Pesquisas Educacionais Anísio Teixeira (INEP). Notas estatísticas: Censo da educação superior - diretoria de estatísticas educacionais (deed), 2017. URL http://download.inep.gov.br/educacao_superior/censo_superior/documentos/ 2018/censo_da_educacao_superior_2017-notas_estatisticas2.pdf\&ved= 2ahUKEwijgtOMt73lAhUCFFAKHS1XC4gQFjAEegQIBBAB\&usg= AOvVaw29BJ4xOrJurpcZKfa1XkM5.

[9] Carolina Marins Santos. Por que as mulheres "desapareceram" dos cursos de computação? fournal da Universidade de São Paulo, 2018. URL jornal.usp.br/?p= 136701.

[10] National Center for Education Statistics (NCES). Degrees in computer and information sciences conferred by degree-granting institutions, by level of degree and sex of student: 1970-71 through 2010-11, 2012. URL https://nces.ed.gov/ programs/digest/d12/tables/dt12_349.asp.

[11] M. H. S. Cruz. A perspectiva de gênero no campo da ciência. chapter Gênero, educação e comunicação, pages 40-56. Editora UFPE, Recife, PE, 2012.

[12] Lourdes Bandeira. A contribuição da crítica a contribuição da crítica feminista à ciência. Estudos Feministas, 16(1):207-228, 2008.

[13] Cléuzio Fonseca Filho. História da computação: O Caminho do Pensamento e da Tecnologia. EDIPUCRS, 2007.

[14] Alvaro Videla. https://medium.com/a-computer-of-ones-own/kathleen-boothmachine-learning-pioneer-7cb8b2ed70c8, 2018.

[15] Anja Drephal. The woman behind wifi, 2016. URL https://fahrplan. events.ccc.de/congress/2016/Fahrplan/system/event_attachments/ attachments/000/003/137/original/The_woman_behind_your_WiFi.pdf\& ved=2ahUKEwi_tbD7qb_lAhWBLFAKHeafDOMQFjASegQIBxAB\&usg= AOvVaw1SG3M1qexyfalLiHSfQiqD.

[16] K. S. Figueiredo and J. C. Santos. Computasseia: Destacando a participação feminina na história da computação. In Anais do XXXVI Congresso da Sociedade Brasileira de Computação, pages 2652-2655, 2016.

[17] Revista Galileu. Katie bouman: conheça a responsável pela primeira imagem de um buraco negro, 2019. URL https://revistagalileu.globo. com/amp/Ciencia/Espaco/noticia/2019/04/katie-bouman-conhecaresponsavel-pela-primeira-imagem-de-um-buraco-negro.html\&ved= 2ahUKEwj2nOC9rr_lAhWvEbkGHQ9nDKgQFjAAegQIAxAB\&usg= AOvVaw1LJII3Wg1905JxWH7qAeia\&ampcf $=1>$

[18] Gilda Olinto. A inclusão das mulheres nas carreiras de ciência e tecnologia no brasil. Revista: ibict, (1):68-77, 2011. URL http://revista.ibict.br/inclusao/article/ view/1667.

[19] Fabíola Nakamura, Ludymila Lobo, Rosiane de Freitas, Taynah Almeida, Ana Lúcia Machado, and Tanara Lauschner. Participação feminina em cursos de computação: um estudo no instituto de computação da universidade federal do amazonas. In XI Women in Information Technology, pages 1233-1237, 2017.

[20] W. O Santos. Mulheres na computação: Uma análise da participação feminina nos cursos de licenciatura em computação. In VI Congresso Brasileiro de Informática na Educação, pages 814-823, 2017.

[21] Juliana Sanguinetto de Sousa, Maykon Chagas de Souza, Marcelo Dornbusch Lopes, and Anita Maria da Rocha Fernandes. Mulheres digitais: Uma análise da participação das mulheres nos cursos de ciência da computação e engenharia de computação no brasil e na universidade univali. In Computer on the Beach, pages 1-10, 2016.

[22] Alyne C. Oliveira, Mirella M. Moro, and Raquel O. Prates. Perfil feminino em computação: Análise inicial. In Anais do XXXIV Congresso da Sociedade Brasileira de Computação, pages 1465-1474, 2014.

[23] M. C. Monard and P. M Fortes, R. Uma visão da participação feminina nos cursos de ciência de computação no brasil. In Memórias del V Congreso de la Mujer Latinoamericana en la Computacion, 2013.

[24] Mark Kasunic. Designing an effective survey. Pittsburgh, PA.: Carnegie Mellon University, 2005

[25] Kitchenham B. A. and S. L. Pfleeger. Guide to advanced empirical software engineering. chapter Personal opinion surveys., pages 63-92. Springer London, London, 2008.

[26] J. C. R. Hauck, C. G. Von Wangenheim, and A. Von Wangenheim. Método de aquisição de conhecimento para customização de modelos de capacidade/ maturidade de processos de software, 2011.

[27] M. S. Litwin. How to Measure Survey Reliability and Validity. SAGE Publication, 1995. 